Japanese Journal of Applied Physics, 36 (7A) (1997) 4297-4298

\title{
Effect of Hydrogenation on Photodarkening in CdS-Doped Glass
}

Tadaki Miyoshi, Koji Nitta, Ken-ichi Towata and Naoto Matsuo

Department of Electrical and Electronic Engineering, Yamaguchi University, Tokiwadai, U be, Yamaguchi 755, Japan

(Received February 7, 1997; accepted May 2, 1997)

The effect of hydrogenation on photodarkening has been investigated in CdS-doped glass to investigate the nature of photoinduced defects using luminescence and electron spin resonance (ESR). Photodarkening disappears after hydrogenation. This indicates that the photoinduced defects are passivated by hydrogen. The possible structures of the defects are considered in this paper.

KEYWORDS: semi conduct or, nanocrystal, quant um dot, phot odarkeni ng, I umi nescence, ESR 
The optical properties of semiconductor-doped glasses have been studied extensively, since these materials have a large optical nonlinearity and a fast response time. Roussignol et al. ${ }^{1)}$ reported that the response time of the nonlinear signal and the luminescence of CdSSe-doped glass was decreased by light irradiation. This photoinduced irreversible process is called photodarkening. Photodarkening is considered to be due to electrons trapped in the glass matrix ${ }^{2,3)}$ or to photoinduced defects, which act as nonradiative recombination centers. ${ }^{4,5)}$ In previous papers,${ }^{6-8)}$ we reported that photodarkening was attributable to photoinduced defects created at the interface region between the semiconductor nanocrystals and the glass matrix. Here, we report the effect of hydrogenation on photodarkening to investigate the nature of photoinduced defects.

The sample mainly investigated was CdS-doped commercial filter glass (Toshiba Y45 ) of about $2.5 \mathrm{~mm}$ thickness. The concentration of $\mathrm{CdS}$ is $0.4 \mathrm{wt} \%$. The glass was exposed to pulsed light from an $\mathrm{N}_{2}$ laser (Usho YKN-900; wavelength $=337.1 \mathrm{~nm}$, pulse duration $=5 \mathrm{~ns}$, peak intensity $=5 \mathrm{MW} / \mathrm{cm}^{2}$, repetition rate $=1 \mathrm{~Hz}$ ) at $300 \mathrm{~K}$ for $30 \mathrm{~s}$. Penetration depth of laser light was estimated from the optical transmittance of the glass. The penetration depth is less than $0.2 \mathrm{~mm}$. The irradiated glass was hygrogenated in a hydrogen atmosphere at $350^{\circ} \mathrm{C}$ for $4 \mathrm{~h}$. Another sample irradiated with the same condition was annealed in air at $350^{\circ} \mathrm{C}$ for $4 \mathrm{~h}$ to investigate the effect of heating during hydrogenation.

Transient characteristics of luminescence were measured using the following apparatus at $300 \mathrm{~K}$. The excitation source was another $\mathrm{N}_{2}$ laser (Laser Photonics LN120; wavelength $=337.1 \mathrm{~nm}$, pulse duration $=0.3 \mathrm{~ns}$, repetition rate $=7 \mathrm{~Hz}$ ). The laser beam was set at an angle of about $30^{\circ}$ to the normal and was focused on an area of about $1 \mathrm{~mm}^{2}$ by a quartz lens (focal length $f=150 \mathrm{~mm}$ ). Since the peak intensity of the laser light was low $\left(50 \mathrm{~kW} / \mathrm{cm}^{2}\right)$, photoinduced spectral changes were not observed. Luminescence was collected normal to the sample surface, focused on the end of an optical fiber by two quartz lenses $(f=50.8 \mathrm{~mm})$, and then led to a $27 \mathrm{~cm}$ monochromator (Jarrel-Ash Monospec 27). Time-resolved luminescence spectra were measured using an optical multichannel analyzer with a gate (Princeton Instruments D/SIDA-700). The minimum gate time was $5 \mathrm{~ns}$. The ESR spectra were measured at $77 \mathrm{~K}$ using an X-band spectrometer (JES FE- 
1X). The first-derivative spectra were obtained by $100 \mathrm{kHz}$ modulation. The $g$-values of the signals were determined using a $\mathrm{MgO}: \mathrm{Mn}$ marker.

The main luminescence band is observed at about $440 \mathrm{~nm}$ in CdS-doped glass, Y-45, at $300 \mathrm{~K}^{8)}$ This band is attributable to the band-to-band or shallow-trapping state-toband transition. ${ }^{9)}$ Noticeable change in the spectral shape of the luminescence is not observed after irradiation, hydrogenation and thermal annealing. On the other hand, the luminescence intensity decreases after irradiation and partly recovers after hydrogenation and annealing. Luminescence intensity ratios are as follows: before irradiation (1), after irradiation (0.49), after hydrogenation (0.89) and after annealing (0.76). Transient characteristics of luminescence also change after irradiation, hydrogenation and annealing. Figure 1 shows the transient characteristics of luminescence from Y-45 at peak wavelength. Intensities at $t=0 \mathrm{~ns}$ are normalized. The decay rate of luminescence from $\mathrm{Y}-45$ after laser irradiation is faster than that before irradiation. This indicates that additional defects are created by laser irradiation. These photoinduced defects act as nonradiative recombination centers and provide additional channels for the recombination of excited carriers, therefore the decay rate of the luminescence is increased. The decay rate of the luminescence recovers its initial value after hydrogenation. On the contrary, the decay rate of the luminescence does not recover after annealing in air. This result indicates that the photoinduced defects are passivated by hydrogen.

ESR spectra were measured to investigate the nature of the photoinduced defects. The ESR signal was not observed in CdS-doped glass of Y-45 before laser irradiation. ESR signals appear after irradiation. Figure 2 shows ESR spectra of Y-45 at $77 \mathrm{~K}$. The ESR signal at approximately $g=1.99$ is considered to be due to the electron traps in the glass. This signal disappears after annealing at $200^{\circ} \mathrm{C}$. However, the decay rate of the luminescence only partially recovers after annealing. ${ }^{8)}$ Thus, the electron traps do not play an important role in the change in the luminescence properties. The signal at approximately $g=1.99$ is similar to that observed in irradiated borosilicate glass: $x \mathrm{CdO}$ $(65-x) \mathrm{ZnO}-17.5 \mathrm{~B}_{2} \mathrm{O}_{3}-17.5 \mathrm{SiO}_{2}, x=5$ and $\left.10 .^{10}\right)$ This signal is assigned to a trapped electron on a $\mathrm{Cd}^{2+}$ ion. Although $\mathrm{Cd}$ and $\mathrm{S}$ form $\mathrm{CdS}$ nanocrystals in glass by thermal treatment at approximately $600-700^{\circ} \mathrm{C}$, a small amount of $\mathrm{Cd}$ may remain in the glass 
matrix. The signal at approximately $g=1.99$ is not observed in glass which does not contain CdS. ${ }^{6)}$ This supports the assignment described above.

The signal at approximately $g=2.01$ is considered to be due to photoinduced defects in the interface region between $\mathrm{CdS}$ nanocrystals and the glass matrix. ${ }^{6,7)}$ The signal at approximately $g=2.01$ is correlated with the decay rate of the luminescence. Thus, the photoinduced defects are related to photodarkening. The ESR signal at approximately $g$ $=2.01$ decreases after hydrogenation. The effect of heating during hydrogenation is not important, since this signal only slightly decreases after thermal annealing in air. Similar results were also observed in Y-44. The signal at approximately $g=2.01$ is similar to that observed in irradiated borosilicate glass: $\left.x \mathrm{CdO}-(65-x) \mathrm{ZnO}-17.5 \mathrm{~B}_{2} \mathrm{O}_{3}-17.5 \mathrm{SiO}_{2} \cdot{ }^{10}\right)$ This signal is assigned to a trapped hole on a nonbridging oxygen atom neighboring on an $\mathrm{Si}$ atom $(\equiv \mathrm{Si}-\mathrm{O} \cdot)$. The ESR signal associated with the nonbridging oxygen atom almost disappears after annealing at $400^{\circ} \mathrm{C} .{ }^{11)}$ The nonbridging oxygen atom reacts with hydrogen, ${ }^{12)}$ which is consistent with our result. Thus, the photoinduced defects are considered to be trapped hole centers in the glass side of the interface region between the CdS nanocrystals and the glass matrix. These defects may act as nonradiative recombination centers.

The effect of hydrogenation was investigated for CdSe-doped borosilicate glass before laser irradiation by Woggon et al. ${ }^{13)}$ They measured the kinetics of induced transmission of the glass. They observed that the time constant of the fast component of the induced transmission for the hydrogenated sample is about twice that as before hydrogenation. In addition, the hydrogenated sample seems to be more resistant to darkening effects. They considered that these results were due to the passivation of interface states caused by hydrogenation. We also investigated the effects of hydrogenation on CdS-doped glass before laser irradiation, but did not observe any noticeable effect of hydrogenation. This indicates that the number of defects in our sample are few before irradiation and are created by irradiation, since the ESR signal is very weak before irradiation and increases after irradiation. On the other hand, the sample used by Woggon et al. ${ }^{13)}$ may have contained many defects before irradiation, therefore they observed effects of hydrogenation in the sample before irradiation. These results indicate that glass composition plays an 
important role in the creation and annihilation of defects.

In summary, the luminescence and ESR spectra of photodarkened CdS-doped glass were measured before and after hydrogenation to investigate the nature of photoinduced defects. The ESR signal associated with the photoinduced defects, which is related to photodarkening, disappears after hydrogenation. The ESR signal of the defect is similar to that of a trapped hole on a nonbridging oxygen atom neighboring on an Si atom.

We are grateful to Dr. X. Zhao of RIKEN (The Institute of Physical and Chemical Research) for carrying out the hydrogenation of the glass and to Professor T. Miki for providing permission to use his ESR spectrometer. 


\section{References}

1) P. Roussignol, D. Ricard, J. Lukasik and C. Flytzanis: J. Opt. Soc. Am. B 4 (1987) 5.

2) V. Ya. Grabovskis, Ya. Ya. Dzenis, A. I. Ekimov, I. A. Kudryavtsev, M. N. Tolstoi and U. T. Rogulis: Sov. Phys. Solid State 31 (1989) 149.

3) J. Malhotra, D. J. Hagan and B. G. Potter: J. Opt. Soc. Am. B 8 (1991) 1531.

4) B. Van Wonterghem, S. M. Saltiel, T. E. Dutton and P. M. Rentzepis: J. Appl. Phys. 66 (1989) 4935.

5) M. Tomita and M. Matsuoka: J. Opt. Soc. Am. B 7 (1990) 1198.

6) T. Miyoshi, K. Towata and N. Matsuo: Jpn. J. Appl. Phys. 33 (1994) 6299.

7) T. Miyoshi, H. Matsuki and N. Matsuo: Jpn. J. Appl. Phys. 34 (1995) 1837.

8) T. Miyoshi, K. Towata, H. Matsuki, N. Matsuo and T. Kaneda: Mater. Sci. Forum 196-201 (1995) 573.

9) K. Misawa, H. Yao, T. Hayashi and T. Kobayashi: Chem. Phys. Lett. 183 (1991) 113.

10) H. Kawazoe, R. Suzuki, S. Inoue and M. Yamane: J. Non-Cryst. Solids 111 (1989) 16.

11) K. Nagasawa, Y. Hoshi, Y. Ohki and K. Yahagi: Jpn. J. Appl. Phys. 25 (1986) 464.

12) D. L. Griscom: J. Non-Cryst. Solids 68 (1984) 301.

13) U. Woggon, M. Muller, I. Ruckmann, J. Kolenda and M. Petrauskas: Phys. Status Solidi B 160 (1990) K79. 


\section{Figure captions}

Fig. 1. Transient characteristics of luminescence from CdS-doped glass, Y-45, at $300 \mathrm{~K}$.

Intensities at $t=0 \mathrm{~ns}$ are normalized. Solid curves were drawn through the data points as a guide for the eyes.

Fig. 2. ESR spectra of CdS-doped glass, Y-45, at $77 \mathrm{~K}$. 
Fig. 1

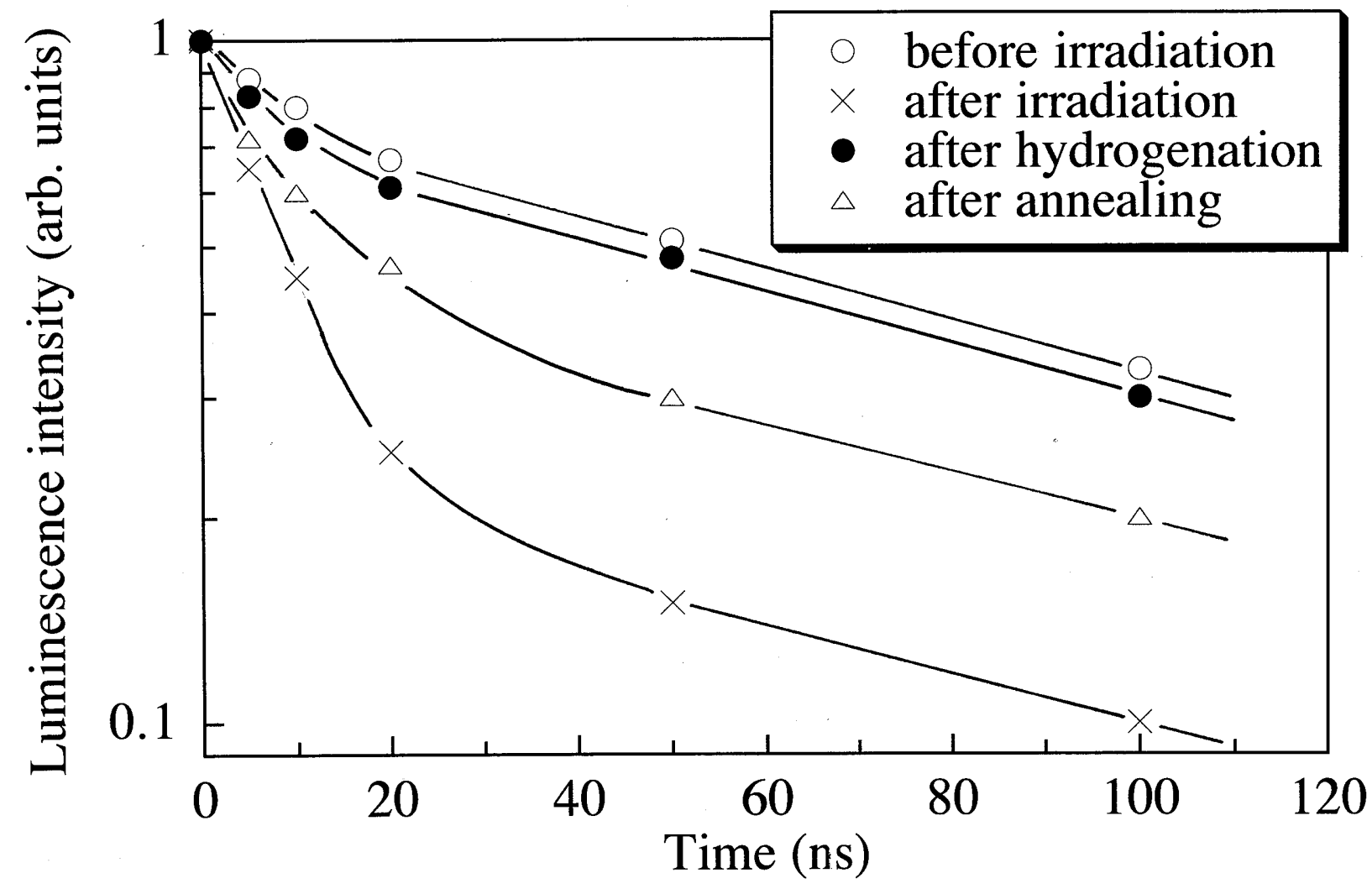

Fig. 2

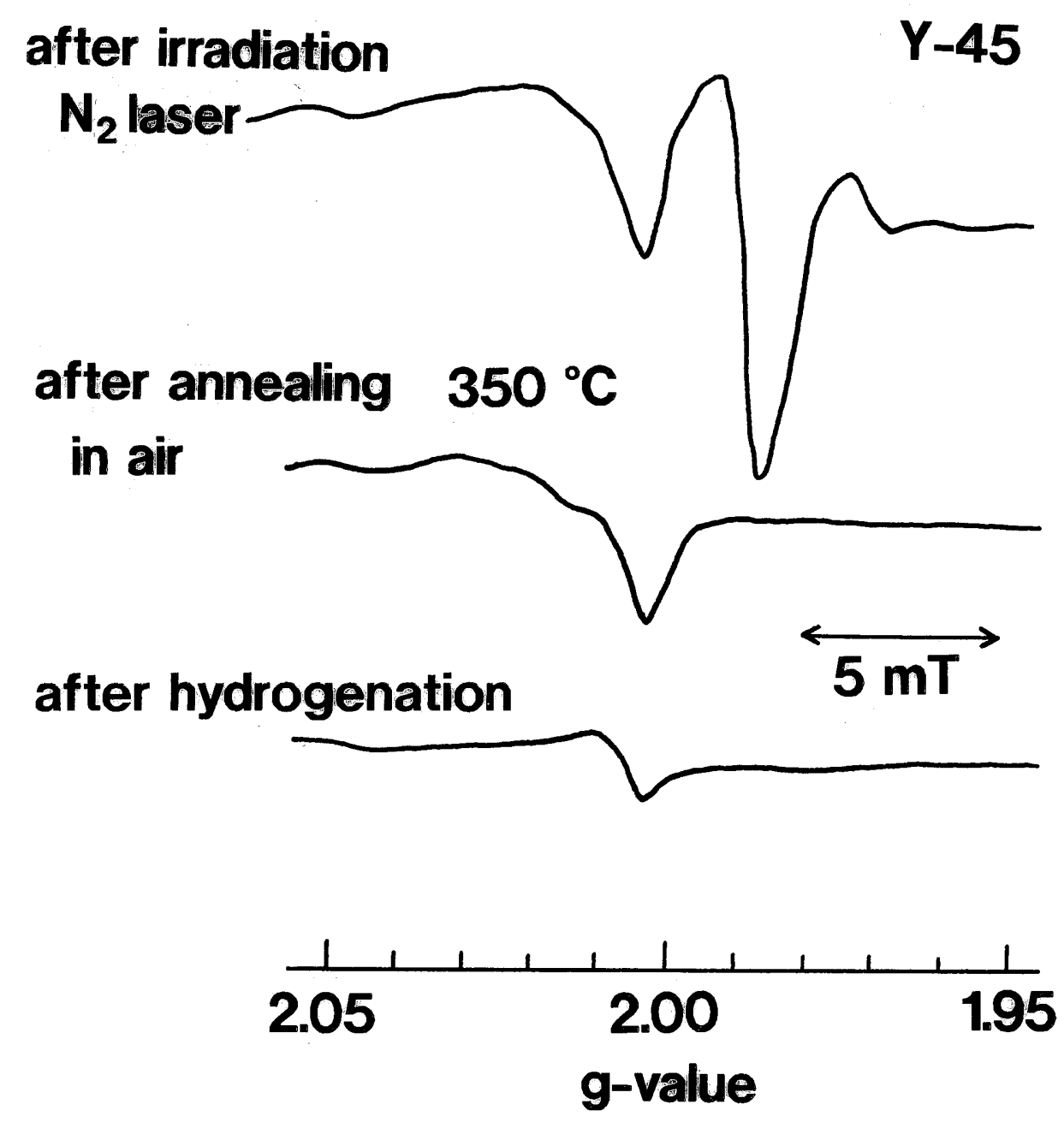

